Artigo Original

\title{
Inclusão escolar na educação física: reflexões acerca da formação docente
}

\author{
Vanderlei Balbino da Costa \\ Programa de Pós Graduação em Educação Especial da UFSCar, São Carlos, SP, \\ Brasil
}

\begin{abstract}
Resumo: A presente pesquisa de mestrado resulta de trabalho realizado entre 2007 e 2008 nas escolas públicas e particulares da cidade de São Carlos/SP com estudantes deficientes visuais matriculados no ensino regular. O objetivo do trabalho foi compreender como vem se dando o processo de Inclusão na Educação Física Escolar dos estudantes deficientes visuais incluídos(as) na Educação Básica. A metodologia utilizada foi a pesquisa qualitativa ancorada nos princípios filosóficos da fenomenologia. Os resultados nos mostraram que o processo de inclusão em relação à Educação Física escolar encontra dificuldades para se efetivar, dada a má preparação e formação docente. As observações junto aos estudantes deficientes visuais também demonstraram o quanto esses(as) estão insatisfeitos com 0 tratamento que os(as) docentes dispensam, no sentido de participar das atividades físicas esportivas e de lazer planejadas nas escolas pelos profissionais que ministram aulas nesse componente curricular. Nossas reflexões são as de que o processo de inclusão na Educação Física escolar poderá demorar muito para ocorrer nas escolas.
\end{abstract}

Palavras-chave: Inclusão Escolar. Educação Física. Formação Docente.

\section{Educational inclusion in the physical education: reflections concerning the teaching formation}

\begin{abstract}
The present Master's Degree study is the result of a work carried out between the years 2007 and 2008 in public and private primary schools in São Carlos, São Paulo State, with blind students regularly registered in elementary and high schools of this municipality. In this work we sought to understand the process of educational inclusion in Physical Education class with blind students in basic education. The methodology used was qualitative research based on the philosophical principles of Phenomenology. The results have shown us that the process of inclusion in Physical Education classes is difficult to accomplish due to bad teaching formation and preparation. The observations carried out along blind students also demonstrated how unsatisfied they are with the treatment that their teachers provide, specially about their sharing on physical activities and recreational sports which are planned by professionals who teach this curriculum component in schools. Our reflections are that the process of inclusion also in Physical Education classes will likely take a long time to happen in all schools.
\end{abstract}

Key Words: Educational Inclusion. Physical Education. Teacher Formation.

\section{Introdução}

O presente estudo é resultado de uma pesquisa de mestrado realizada entre os anos de 2007 e 2008 nas escolas da rede básica da cidade de São Carlos/SP com estudantes deficientes visuais incluídos(as) no ensino regular. Neste sentido, abordarei neste artigo algumas questões que refletem sobre a capacitação/ qualificação docente, em especial a formação dos profissionais da Educação Física Escolar.

Ao longo da minha convivência escolar, fui levado a pensar que a Educação é o fio condutor para que possamos nos tornar cidadãos conscientes. A educação libertadora, humana e humanizante, na perspectiva da inclusão, não pode ignorar o outro, o dessemelhante, o estranho, enfim, aquele que se encontra às margens da sociedade.

Nesse sentido, Santos e Paulino (2008) fazem a seguinte consideração:

Acreditamos que está na educação, sem dúvida, a principal ferramenta para a transformação social verdadeira que tanto almejamos. Nos dias de hoje as desigualdades sociais e o desrespeito às diferenças são banalizados em nosso cotidiano, e a escola, sem dúvida, reflete e reproduz estas relações. (p.11).

No mundo moderno, globalizado, sem fronteiras, ligado por rede de informação, penso que um dos princípios fundamentais da Educação nos sistemas inclusivos é garantir direitos, 
acesso, sucesso e permanência de todos os(as) estudantes com deficiências no ensino regular.

Não é difícil perceber que nos cursos de formação docente há uma escassez de conteúdos e, por assim dizer, disciplinas, bem como habilitações que possam contribuir com os docentes em sua formação. Nesse sentido, quando estes(as) recém formados saem das universidades e ingressam na Educação Básica, vão se deparar no ensino regular com uma realidade que está muito presente: o processo de inclusão escolar.

Visando superar essas lacunas nos cursos de formação para a Educação Básica, o conjunto de mudanças propostas pelo Parecer CNE/CP 009/2001 (BRASIL, 2001) configuraram-se de fundamental importância na medida que "estabeleceu- se a preocupação com a profissão docente e a garantia de que novas modificações precisarão ser feitas para legitimar essa área da docência" (BENITES e col., 2008, p.351).

Ao me referir ao Brasil, é premente a falta de curso de formação que prepare docentes de Educação Física para atuarem na Educação Básica com pessoas deficientes contrariando determinações do Parecer CNE/CP 009/01 (BRASIL, 2001). Por sua vez, é raro nas licenciaturas vermos programas que preparem, qualifiquem e habilitem docentes no sentido de enfrentar essa realidade educacional.

Frente a essa problemática é possível aferir que na Educação Física escolar, estão presentes os traços da segregação, exclusão e marginalização social.

Pensar a escola no novo milênio, é pensar nas múltiplas possibilidades que esta tende a oferecer aos educandos. Para tanto, é papel da escola valorizar as diferenças, a singularidade, enfim, abraçar a diversidade na pluralidade e respeitar princípios conforme destaca Barroso (2006):

Para isso, é importante atentar que a escola
enquanto organização constitui uma realidade
complexa, dividida entre múltiplas atividades
sociais de que se destacam: a educação, a
instrução, a formação, a animação, a guarda,
a alimentação, o lazer, o apoio social, o
convívio intra e intergeracional, a ação
comunitária etc. (p.290)

A promoção de uma escola inclusiva, em especial ao nos referirmos à cultura, ao esporte $e$ ao lazer, se faz com estrutura educacional adequada, sem barreiras atitudinais, sociais, arquitetônicas que possam impedir o acesso dos(as) deficientes ao espaço escolar.

\section{Objetivo}

Compreender como vem se dando o processo de Inclusão na Educação Física Escolar dos estudantes deficientes incluídos(as) na Educação Básica. Sendo assim, busquei investigar como se dá o processo de inclusão na Educação Física escolar dos Deficientes Visuais no ensino regular.

\section{Método}

A pesquisa de mestrado utilizou-se da metodologia qualitativa que, de acordo com Negrine (2004), significa:

A base analógica desse tipo de investigação se centra na descrição, análise e interpretação das informações recolhidas durante 0 processo investigatório, procurando entendêlas de forma contextualizada. Isso significa que nas pesquisas de corte qualitativo não há preocupação em generalizar os achados (p.61)

Dentre as possibilidades metodológicas qualitativas busquei, na fenomenologia, inspiração e fundamentação. De acordo com Husserl (1975) a fenomenologia busca a obtenção de uma compreensão, de uma consciência de alguma coisa e então não estabelece critérios de verdade e/ou falsidade diante das proposições dos colaboradores. A verdade aqui considerada é a verdade do ser, é o fazer-se manifesto. A realidade ocorre através da relação existente entre o compreendido e o comunicado, assim sendo, é perspectival.

Para Martins (1992) a fenomenologia é:

(...) principalmente, um nome que se dá a um movimento cujo objetivo precípuo é a investigação direta e a descrição de fenômenos que são experienciados pela consciência, sem teorias sobre a sua explicação causal e tão livre quanto possível de pressupostos e de preconceitos (p.50).

A pesquisa fenomenológica propõe o "ir à coisa mesma", ou seja, àqueles que experienciam em seu mundo-vida o fenômeno interrogado e podem falar sobre ele (MARTINS E BICUDO, 1989; MACHADO, 1994; GONÇALVES JUNIOR, 2003), sendo seu objetivo:

(...) buscar a essência ou a estrutura do fenômeno, que deve se mostrar nos discursos (descrições) dos sujeitos. Há, portanto, grande ênfase na natureza descritiva do fenômeno pesquisado. Os discursos, referindo-se às experiências que os sujeitos vivenciam no seu mundo-vida, contêm uma intencionalidade na 
existência destes sujeitos (MACHADO, 1994, p.45).

Os autores salientam que na pesquisa fenomenológica não se procura uma explicação para o fenômeno interrogado, mas sim uma compreensão do mesmo, pois este não se finda em uma única realidade, mas em tantas quantas forem suas comunicações e interpretações. Deste modo, conforme destaca Gonçalves Junior (2003), quando o fenômeno a estudar possui o dom da intencionalidade convém falar em compreensão (deixar que se mostre do interior), ao invés de explicação (análise do exterior), já que o humano não é mero objeto, mas sujeito, e, enquanto tal, expressa uma intenção e uma subjetividade, o que precisamente nos torna humanos em essência.

\section{Procedimentos Metodológicos}

Ao levantar a questão de pesquisa, objetivos e opção metodológica, a primeira atitude foi dirigir à Secretaria Municipal de Educação e Cultura (SMEC) e na Diretoria Regional de Ensino (DRE), procurar as coordenadorias dessas instituições a fim de descobrir em quais escolas havia matrículas de estudantes deficientes visuais freqüentando o ensino regular.

Saliento que dois desses estudantes são de escola pública estadual, dois de escola pública municipal e dois de escola particular, sendo apenas uma estudante do sexo feminino e maior de idade.

De posse destas informações realizei aproximação inicial com as escolas que abrigam estudantes deficientes visuais, que aceitaram a realização desta inserção.

A inserção no ambiente escolar se deu de modo cuidadoso e dialogado com a comunidade através do convívio freireano. De acordo com Oliveira e Stotz (2004) isso significa uma vivência diária, próxima, afetiva e comprometida. Nela as pessoas se colocam abertamente e o conhecimento é mais autêntico. Por meio do convívio é possível identificar as diferenças que aparecem nas percepções de tempo e de espaço, nas percepções de mundo e dos modos de nele viver, conviver, construir, reconstruir. Segundo a mesma autora e autor "conviver se aprende convivendo e para essa convivência há algumas moedas: simpatia, confiança, humildade, sensibilidade, respeito, flexibilidade em relação aos tempos" (p.14-15).
De acordo com Freire (1987), "o que fazer não pode ocorrer sem a reflexão do seu e a dos outros, se o seu compromisso é a libertação" (p.127). É nesse prisma que a dialogicidade configurou-se como um importante instrumento, pelo qual pude comunicar com eles, junto a eles, pela criação, recriação, construção, reconstrução, trocando experiências, tomando parte da sua vida, do outro, sendo por eles admitido, inserido no grupo, participando e vivenciando coletivamente. Diálogo entre colaboradores, constituindo-se ao mesmo tempo busca e processo de humanização, denúncia e anúncio.

Em toda a inserção foram realizadas observações nas escolas e em seu entorno como um todo e, principalmente, no tempo/espaço das aulas de turmas que têm freqüência de estudantes deficientes visuais, buscando aperfeiçoar o olhar junto a comunidade escolar que é, em certa medida, estranha, sendo também eu, em certa medida, estranho a ela. Desta forma, Larrosa Bondía (2002) comenta:

A experiência, a possibilidade de que algo nos aconteça ou nos toque, requer um gesto de interrupção, um gesto que é quase impossível nos tempos que correm: requer parar para pensar, parar para olhar, parar para escutar, pensar mais devagar, olhar mais devagar, e escutar mais devagar... (p.24).

Realizei, durante o segundo semestre de 2007, observações em sala de aula junto aos seis estudantes deficientes visuais matriculados no ensino regular, fundamental e médio, registrando sistematicamente em notas de campo as minhas percepções acerca desta convivência. Neste prisma Bogdan e Biklen (1994) afirmam que:

(...) as notas de campo consistem em dois tipos de materiais. O primeiro é descritivo, em que a preocupação é a de captar uma imagem por palavras do local, pessoas, ações e conversas observadas. O outro é reflexivo - a parte que apreende mais o ponto de vista do observador, as suas idéias e preocupações (p.152).

Ressalto que as observações nessas três escolas foram realizadas no segundo semestre de 2007. No primeiro semestre de 2008 realizei entrevistas, momento em que os estudantes haviam sido promovidos para a série seguinte.

As entrevistas foram realizadas a fim de aprofundar a compreensão daquilo que observei nas três escolas e o que os estudantes deficientes visuais percebem acerca da convivência escolar na Educação Física com seus(as) docentes no ensino regular. 
Quadro 1. Características dos colaboradores entrevistados

\begin{tabular}{|c|c|c|c|c|c|c|c|}
\hline Colaboradores & Sexo & Idade & $\begin{array}{c}\text { Grau da } \\
\text { deficiência }\end{array}$ & $\begin{array}{c}\text { Nível } \\
\text { escolar }\end{array}$ & $\begin{array}{c}\text { Modalidade } \\
\text { escolar }\end{array}$ & $\begin{array}{c}\text { Data da } \\
\text { entrevista }\end{array}$ & $\begin{array}{c}\text { Local da } \\
\text { entrevista }\end{array}$ \\
\hline C1 & $\mathrm{M}$ & 16 & DVT & $7^{\text {a }} \mathrm{EF}$ & Municipal & $01 / 06 / 2008$ & Residência \\
\hline C2 & $\mathrm{M}$ & 17 & $\mathrm{BV}(15 \%)$ & $2^{\circ} \mathrm{EM}$ & Estadual & $02 / 06 / 2008$ & Residência \\
\hline C3 & $\mathrm{M}$ & 16 & $\mathrm{DVT}$ & $8^{\mathrm{a}} \mathrm{EF}$ & Municipal & $18 / 06 / 2008$ & Sala de Recurso \\
\hline C4 & $\mathrm{M}$ & 14 & $\mathrm{BV}(20 \%)$ & $8^{\mathrm{a}} \mathrm{EF}$ & Particular & $21 / 06 / 2008$ & Residência \\
\hline C5 & $\mathrm{M}$ & 17 & $\mathrm{DVT}$ & $1^{\circ} \mathrm{EM}$ & Particular & $27 / 06 / 2008$ & Residência \\
\hline C6 & $\mathrm{F}$ & 27 & DVT & $2^{\circ} \mathrm{EM}$ & Estadual & $28 / 06 / 2008$ & UNIMED \\
\hline
\end{tabular}

C- Colaborador DVT- Deficiente Visual Total BV- Baixa Visão EF- Ensino Fundamental EM- Ensino Médio

As entrevistas foram realizadas individualmente e registradas, mediante as seguintes questões suleadoras:

- Como é o seu cotidiano na sala de aula e na escola como um todo?

- Como é sua relação de convivência com os(as) docentes do componente curricular Educação Física Escolar?

- Você realiza alguma atividade física escolar?

- Você se sente incluído nas aulas de Educação Física Escolar? Comente.

Inspiradas na fenomenologia, as entrevistas foram transcritas rigorosamente na íntegra, mantendo-se a fala original dos(as) estudantes deficientes visuais conforme suas pronúncias, ou seja, mantive o discurso ingênuo, entendido como dado genuíno, original primário ou verbatin (GONÇALVES JUNIOR, 2003).

Ressalto que esse estudo foi realizado com seis estudantes deficientes visuais incluídos(as) no ensino regular, que receberam e assinaram o Termo de Consentimento Livre e Esclarecido (TCLE). Deste modo, a pesquisa realizou-se mediante aprovação do Parecer no 403/2008 do Comitê de Ética da Universidade Federal de São Carlos (CEP/UFSCar).

\section{Resultados e Discussões}

Enquanto estudante deficiente visual, fruto de uma escola que sempre foi excludente, seletista e conservadora, pude constatar nas minhas observações como pesquisador, bem como nas entrevistas que os resultados obtidos nessa pesquisa de Mestrado me levaram a pensar que 0 processo de Inclusão ainda vem se efetivando de forma parcial, pois percebi a necessidade de formação docente de nível superior para a Educação Básica.

Me deparei com alguns depoimentos de estudantes deficientes visuais que não estão sendo incluídos nas atividades físicas esportivas e de lazer planejadas pelos(as) docentes. O processo de Inclusão Escolar dos(as) estudantes com deficiência visual nas aulas de Educação Física é um problema porque os(as) docentes alegaram não estarem preparados para promover a participação destes(as) nas atividades. A docente de Educação Física Escolar me confessou que "a inclusão não vem ocorrendo porque a estrutura da escola não permite $e$ também porque os(as) docentes não estão preparados e qualificados para exercer esta função" (COSTA, 2009, Apêndice C, p.164).

No que tange a escola, concordo com a docente de que esta não esta adequada ao processo de inclusão seria relevante que, pelo menos, o sistema educacional pudesse adaptá-la, no sentido de possibilitar que as pessoas deficientes pudessem participar das atividades físicas, esportivas e de lazer desenvolvidas pelos(as) docentes do componente curricular de Educação Física. Acerca dessa assertiva, Lopes e Valdés (2003) alertam que:

Há uma necessidade veemente por parte dos professores em participar de um programa de capacitação para atuar junto com alunos deficientes: - As escolas carecem de infraestrutura adequada, os materiais são escassos e não atendem a condições mínimas para realizar uma aula de Educação Física (p.206).

Ao me referir a necessidade de uma formação especifica para os(as) docentes que atuam na educação básica, é recorrente o discurso de que esses(as) não estão preparados para atuar com estudantes deficientes visuais. Além disso, detectei que alguns docentes são relutantes em praticar alguma atividade esportiva com estudantes deficientes visuais, pois alegam insegurança e medo de que estes se machuquem (COSTA, 2009, Apêndice C, p.184).

Numa das observações em campo tive a oportunidade de conversar com uma docente de Educação Física, de escola municipal em uma de suas aulas ministrada na quadra poliesportiva. 
Ela comentou que não tem bola com guizo ou quadra adaptada e ainda que não se sente preparada para trabalhar com estudantes com deficiência, principalmente quando se refere às práticas esportivas (COSTA, 2009, Apêndice C, p.188).

Diante desta constatação, Reid (2000), citado por Silva e col. (2009) propõem:

Não obstante, há a possibilidade de que, em algum período da trajetória pedagógica da formação do professor de Educação Física, este possa entrar em contato com alunos que apresentam necessidades educacionais especiais, sendo, pertinente se repensar os programas de preparação profissional, caso os docentes continuem a passar por experiências limitadas e de inadequação no ensino para p.n.e.e (p. 485).

De acordo com a proposta dos autores, isso será de grande relevância quando todos os cursos de formação conseguirem incluir em seus currículos de formação disciplinas que possam contemplar a diversidade, em especial quando me refiro à educação dos diferentes.

Nos diversos níveis de ensino, tenho percebido que há uma lacuna nos cursos de formação de docentes sobre a temática da inclusão escolar na Educação Física. Isso se torna evidente na observação de Vitalino (2007) ao afirmar:

\begin{abstract}
A inclusão dos estudantes com necessidades educacionais especiais (NEE), nos diversos níveis de ensino, depende de inúmeros fatores, especialmente, da capacidade de seus professores de promover sua aprendizagem e participação. E aí surge 0 questionamento: Os professores estão preparados para assumir tal responsabilidade?
\end{abstract}

Ao examinarmos essas análises, notamos que [...], os professores que atuam nos cursos de formação de professores, os denominados de licenciatura, também não estão preparados ( $p$. 400).

Em outro momento de convivência, registrei em notas de campo que outra docente de Educação Física, de escola estadual, salientou não estimular os(as) estudantes com deficiência visual a realizarem práticas corporais, pois não tem nenhuma habilitação para exercer essa função, tendo em vista que nunca recebeu treinamento específico nas escolas do Estado ou do Município nas quais trabalha (COSTA, 2009, Apêndice C, p.234). Nesse aspecto é que insisto ser relevante discutir a formação de professores para as mais diferentes áreas de conhecimentos como, por exemplo, a educação dos diferentes no contexto da escola.

Contrariamente ao relato da docente, em se tratando do componente curricular de Educação Física escolar, por exemplo, este se constitui em um elemento relevante ao processo de inclusão, seja ele nos esportes, na cultura e no lazer. Partindo dessa premissa, Rodrigues (2003) faz a seguinte consideração:

(...) a EF seria uma área curricular mais facilmente inclusiva devido à flexibilidade inerente aos seus conteúdos o que conduziria a uma maior facilidade de diferenciação curricular.

[...] A EF é julgada uma área importante de inclusão dado que permite uma ampla participação mesmo de alunos que evidenciam dificuldades (p.77-78).

Diante dessa percepção, evidenciei a expectativa que os estudantes têm de participar das práticas esportivas, culturais e de lazer promovidas pela escola. Nessa perspectiva Lopes e Valdés (2003), consideram: "Há uma grande expectativa por parte dos alunos em participar de aulas de Educação Física" (p.206). Em se tratando do componente curricular de Educação Física escolar, uma das estudantes entrevistada declara:

Ao contrário de outros colegas deficientes, nas aulas de educação física, eu sempre participei, claro que não de todas as atividades. Eu tive um professor muito bom, quando eu não podia jogar determinado esporte, ele adaptava alguma atividade para mim, ou seja, ele mesmo jogava comigo (COSTA, 2009, Apêndice D, p.248).

No entanto, outra questão registrada nas notas de campo ou citada pelos(as) entrevistados(as) diz respeito à formação docente. A entrevistada VI, por exemplo, afirma que para que os estudantes com deficiência visual se sintam incluídos no ensino regular é preciso:

(...) melhorar a convivência com os professores, que deveriam buscar mais 0 aprendizado, para que nós nos sentíssemos mais à vontade. Porque em certo momento eles ficam tão em dúvida, que acabam embananando a cabeça da gente, enfim, acho que falta realmente formação e preparação para lidar com a gente, com as pessoas deficientes (COSTA, 2009, Apêndice D, 8-C, p.248).

Neste aspecto, Castellanos, citado por Lopes e Valdés (2003), declara que, em ordem de prioridade, foram elencadas as seguintes principais dificuldades para a inclusão na escola: 
"Má preparação dos docentes; Sistemas educativos inadequados; Falta de metodologia apropriada e Falta de conhecimentos dos docentes para trabalhar com crianças deficientes" (p.196).

Diante dessas reflexões, pude notar que esses(as) estudantes com deficiência visual insistem em participar das aulas de Educação Física, conforme relato de um dos entrevistados incluído no ensino regular:

Em educação física, por exemplo, a professora manda eu jogar dama, algo que não me interessa. Jogar dama eu jogo em casa porque na escola eu queria fazer outros exercícios e não jogar dama. Só que na escola isso não dá, isso não é possível, pois não tem a preparação para isso e geralmente os alunos também querem jogar 0 futebolzinho deles como se educação física fosse só isso jogar futebol (COSTA, 2009, Apêndice D, p.240).

Por sua vez Furini (2006), citando Mittler, escreve que:

(...) a principal barreira à inclusão encontra-se na percepção dos professores de que as crianças especiais são diferentes e requerem um conhecimento, um treinamento e escolas especiais. [...] Este autor acredita que os professores precisam de oportunidades para refletir e discutir sobre as propostas de mudança que mexem com seus valores e com suas convicções (p.80).

Essa premissa me leva a pensar que, na escola e, por sua vez, na Educação Física escolar, iremos deparar com exclusão, conforme alerta Rodrigues (2003):

(...) encontramos na EF uma dupla genealogia de razões que podem conduzir à exclusão. [...] A Educação Física é obviamente influenciada por esta cultura escolar e segue e participa nesta exclusão. Esta cultura competitiva constitui uma segunda fonte de exclusão (p.80-81).

Nas minhas observações, bem como no momento em que realizei as entrevistas, um dos estudantes, deficiente visual regularmente matriculado em uma escola pública municipal, relatou que:

$\mathrm{Na}$ aula de educação física é o seguinte, a professora, ela assim, ela passa jogos de basquete, vôlei, futebol e os estudantes não podem dar atenção só pra mim, eles têm que fazer as aulas todas, porque o problema é que é uma aula só também de educação física dois dias, quinta a $1^{\underline{a}}$ aula e de sexta a $5^{\underline{a}}$ aula, então isso já dificulta muito pra mim, mas eu gosto sim, eu gosto de ir pra quadra ouvir, né? Eles jogando, escutar, eu gosto, né? Isso é bom pra mim (COSTA, 2009, Apêndice D, p.237-238).
Diante do relato, torna-se evidente que a prática de alguns profissionais da Educação Física escolar, não condiz com o processo de inclusão. Pelo contrário, de acordo com Rodrigues (2003) o papel da Educação Física Escolar é:

a) A Educação Motora proporcionada através da disciplina curricular de EF é um direito. Não é uma opção descartável. Porque é um direito o nosso ponto de partida tem de ser que nenhum aluno pode ser dispensado dele.

b) [...] Se os futuros profissionais forem formados para fomentar a competição, [...] como poderemos esperar que este profissional incentive nos seus alunos a cooperação, o respeito e o valor da diferença e a solidariedade?

c) $\mathrm{O}$ apoio dado aos professores de EF, [...] deve ser um apoio especializado...

d) A disciplina curricular de EF pode, com rigor e com investimento, ser efetivamente uma área-chave para tornar a educação mais inclusiva e pode mesmo, ser um campo privilegiado de experimentação, de inovação e de melhoria da qualidade pedagógica na escola. (p.83).

Nos processos de inclusão escolar, tem sido recorrente o discurso de que um dos entraves à inclusão são exatamente problemas na formação docente. Frente a essa assertiva, Castellanos, citado por Lopes; Valdéz (2003), faz a seguinte consideração:

[...] entende-se que é necessário desencadear estudos que possam contribuir para uma formação complementar especial do professor de Educação Física que atenda às necessidades educacionais especiais tanto do aluno deficiente auditivo como de outras deficiências, favorecendo uma inclusão de qualidade. E quando se fala em processo de inclusão, já é um motivo que leva ao aprimoramento da formação profissional dos professores, constituindo um motivo para que a escola se modernize em prol de uma sociedade a qual não deverá haver espaços para preconceitos, discriminação, barreiras sociais e/ou culturais (p.196).

Os argumentos aqui apontados legitimam a tese de que realmente na escola os(as) docentes precisam de formação em serviços, vivências, convívio com as diferenças, enfim, experiências com essa nova realidade: o processo de inclusão escolar no ensino regular.

Acerca dessa precária formação docente nos cursos de graduação e licenciatura, penso ser relevante incluir aqui também os(as) profissionais da área de Educação Física, pois afirmam que, ao receber em sua sala de aula estudantes deficientes visuais, devem estar preparados, 
qualificados e habilitados para exercer esta função. Nesse sentido, Lopez e Valdés (2003) fazem a seguinte observação:

Todos são incisivos em afirmar que qualquer profissional que for lidar com alunos que necessitem de um atendimento diferenciado, precisam, e isso é fundamental na opinião deles, de uma preparação, uma capacitação, para subsidiar, para enriquecer o trabalho para que o mesmo se torne produtivo, prazeroso e principalmente que atenda as reais e naturais aspirações destes alunos (p.204).

Penso que, "mal dita", a inclusão vem provocando alguns conflitos entre gestores, administradores e, por assim dizer, docentes que atuam na Educação Básica. Nos cursos de licenciatura, o discurso recorrente é o da precária formação, em especial, quando me refiro à formação de docentes para atuarem no Ensino Fundamental e Ensino Médio.

Partindo dessa premissa, o processo de inclusão no ensino regular, em especial ao se referir aos cursos de formação docente para atuar na Educação Básica, parece não ter preocupação com a qualidade de ensino dos estudantes. Nesse sentido, Vitalino (2007) observa:

Outra concepção que dificulta a igualdade de oportunidades é o fato dos professores não se responsabilizarem pela aprendizagem do aluno. Normalmente, [...] os professores não percebem que o "processo de ensinoaprendizagem é um processo repartido, interativo e de responsabilidade mútua do professor e do aluno" (p.402).

Ao me deparar, com os(as) docentes que estão atuando na educação básica, em especial, quando estes(as) estão tendo em suas salas de aula estudantes deficientes visuais, é recorrente 0 discurso de que não estão preparados(as) para trabalharem com esses(as) no ensino regular. Por sua vez, os(as) docentes são unânimes em afirmar que, no processo de formação para atuar na Educação Básica, não tiveram disciplinas que os preparassem, qualificassem e habilitassem para a promoção da Inclusão Escolar.

Diante do exposto pelos(as) docentes que estão atuando na Educação Básica, os avanços acerca da formação ganham maior ênfase após a publicação do Parecer CNE/CP 009/2001 (BRASIL, 2001) que prioriza algumas questões que contribuem para melhorar a atuação desses(as), principalmente quando são abordadas:

[...] questões relacionadas com a formação de professores, priorizando-se a competência como núcleo orientador da formação e também a possibilidade e a necessidade de uma formação vinculada com a atuação profissional e a pesquisa (BENITES e col., 2008, p.351).

Diante dessa premissa, as políticas públicas de educação têm se esforçado no sentido de poder promover no sistema de ensino o ingresso de todas as pessoas em idade escolar. Tais esforços, nem sempre vem se configurando, pois existem grupos que se encontram fora desse processo.

Em se tratando da educação das pessoas com necessidades especiais, por exemplo, as Diretrizes Curriculares Nacionais (BRASIL, 2001) para o sistema de ensino propõem que:

A educação básica deve ser inclusiva, no sentido de atender a uma política de integração dos alunos com necessidades educacionais especiais nas classes comuns dos sistemas de ensino. Isso exige que a formação dos professores das diferentes etapas da educação básica inclua conhecimentos relativos à educação desses alunos (BRASIL, PARECER CNE/CP 009/2001, p.26).

Isso a meu ver legitima a necessidade de uma formação docente voltada especificamente para a inclusão dos(as) estudantes com necessidades educacionais especiais no âmbito da escola.

Por sua vez, esse discurso está de certa forma fundamentado na alegação de que a formação para a Educação Básica é precária, principalmente em se tratando da preparação docente para atuar no ensino regular com pessoas deficientes. Deste modo, Vitalino (2007) observa que "esta mobilização e/ou sensibilização é de fundamental importância para que a educação inclusiva possa consolidar-se aos poucos [...] e se expandir para outros níveis de ensino e para a sociedade de maneira geral" (p.411).

Penso, porém, que não é possível disseminar a idéia de que a culpa pelo fracasso da inclusão na escola, nos esportes e no lazer é somente dos(as) docentes. Obviamente que não, afinal, a ação educativa não é uma tarefa apenas do corpo docente. Há, na escola, outros segmentos também responsáveis pela inclusão. Penso que a inclusão não é uma tarefa apenas de alguns; ao contrário, ela constitui-se numa ação educativa plural de todos e para todos. Partindo dessa premissa, Costa (2009) afirma:

Não queremos aqui culpar os(as) docentes, pois estes(as) também são reflexo de um sistema que cuida muito mal das pessoas, 
que pouco as valoriza, enfim, que quase sempre não lhes garante as devidas condições ao seu processo de formação. No entanto, nos sistemas educacionais inclusivos é papel fundamental dos(as) docentes estarem preparados, qualificados e habilitados para avaliar pontos que possam oportunizar e promover o desenvolvimento dos estudantes no sentido de garantir que estes(as) possam ser capazes de conquistar sua autonomia, bem como sua liberdade no contexto da escola. Obviamente, os(as) docentes, por mais que não sejam os culpados pelo fracasso escolar, devem se preparar para propiciar a todos os(as) estudantes acesso, sucesso e permanência na escola, garantindo Ihe independência pessoal, social e, por assim, dizer profissional. (p.135)

Ao pensar na escola, em sua estrutura funcional, bem como na configuração de seus componentes curriculares, é possível verificar que o processo de inclusão seria e teria maior flexibilidade, visto que a educação do diferente deve estar permeada por múltiplas ações pedagógicas diferenciadas.

É obvio que a Educação Física, quando bem planejada no contexto da escola, atrai a atenção de todos, inclusive das pessoas com deficiências que estão incluídas no ensino regular. $O$ argumento de que os(as) docentes da Educação Física desenvolvem atitudes mais positivas junto aos estudantes parece equivocado.

Esta atitude positiva deve ser de todos(as) dentro do sistema educacional, mesmo porque a escola não é feita apenas pelos profissionais da Educação Física, mas também por um conjunto de docentes e demais segmentos que pensam, agem e refletem qual é a melhor forma de incluir sem excluir e marginalizar. Diante das reflexões que fiz no decorrer dessa pesquisa, penso que isso incorre em outros problemas, tais como:

- A falta de estímulos aos docentes em incentivar os(as) estudantes a participarem das atividades esportivas e de lazer;

- Há impregnado no imaginário de alguns(mas) docentes o estigma de que a Educação Física não é importante para a escola;

- Em minhas percepções no decorrer desse estudo registrei ainda um descrédito acentuado por parte dos(as) docentes frente às políticas públicas de inclusão escolar;

- Ao dialogar com os(as) docentes do componente curricular de Educação Física notei que não há prioridade destes(as) ao elaborar seu planejamento, daí não se priorizam os deficientes.

Frente a tais assertivas Lopes e Valdés (2003) observam:

A disciplina de Educação Física não é considerada importante pelas escolas e por isso as mesmas não priorizam ações para dinamizá-la. Há um descrédito generalizado por parte dos professores sobre políticas públicas educacionais, tanto a nível local (escola) quanto às secretarias de educação e isso gera uma insatisfação e pouca motivação por parte dos professores a não realizarem planejamento de aulas e a um não acompanhamento sistemático tanto coletivo como individualizado do desenvolvimento do aluno (p.206).

Perdura a idéia entre alguns segmentos da escola de que as pessoas deficientes não estão estimuladas a participar das atividades físicas esportivas e de lazer. Diante dessas reflexões, essa premissa não se configura. Ao contrário, os(as) estudantes deficientes visuais incluídos no ensino regular, são unânimes em dizer que gostariam muito de poder participar desse conjunto de atividades físicas, esportivas e de lazer junto a seus colegas de sala.

\section{Considerações}

A intenção, nesse estudo, foi analisar a prática social da convivência escolar entre estudantes deficientes visuais e seus docentes, em especial ao me referir ao componente curricular de Educação Física Escolar. Assim, procurei também observar acerca dos(as) docentes aspectos como:

- Sua formação inicial e continuada;

- Suas características no que diz respeito às atitudes frente às diferenças entre seus alunos;

- Como reage às dificuldades dos alunos;

- Se acredita, firmemente, que todos os alunos são capazes de aprender, bem como que há aqueles que aprendem por motivação própria e descompassada do coletivo.

Ao olhar para as propostas que estão presentes nas Diretrizes Curriculares Nacionais (BRASIL, 2001), percebem-se algumas lacunas acerca da formação profissional para atuar nas diferentes etapas de formação dos nossos educandos. Isso pode ser observado quando:

As temáticas referentes à Educação de Jovens e Adultos, à Educação Especial e Educação Indígena, raramente estão presentes nos cursos de formação de professores [...]. A construção espacial para alunos cegos, a singularidade lingüística dos alunos surdos, as formas de comunicação dos paralisados cerebrais, são, entre outras, temáticas a serem consideradas (p.27).

É necessário salientar neste estudo que para que a inclusão possa ocorrer é imprescindível que os(as) docentes possam se preparar, se qualificar e se habilitar para que na escola a inclusão do deficiente, do estranho, do dessemelhante não se 
constitua em obstáculos ao ensino. Partindo desta premissa, Carvalho (2006) alerta que:

Precisamos colocar os pingos nos "is" e entender que a inclusão envolve a reestruturação das culturas, políticas e práticas de nossas escolas que, como sistemas abertos precisam rever suas ações, até então, predominantemente elitistas e excludentes (p.158).

Nessas reflexões, identifiquei em observações, bem como nos diálogos que tive com alguns docentes a necessidade de formação continuada em serviços desses(as), reflexão de toda a comunidade escolar acerca da Inclusão, investimentos em equipamentos e, por fim, adaptação dos currículos escolares a essa nova realidade. Conforme ressalta González (2007):

Adaptar o ensino às crianças, atendendo as diferenças individuais (suas necessidades e peculiaridades), é um tema que sempre preocupou os profissionais da educação. É provável que essa preocupação tenha se tornado menor nos últimos anos. A questão é adaptar a educação ao indivíduo, e não o indivíduo à educação, submetendo-o a um caminho de segregação, fracasso ou marginalização (p. 29).

As experiências previamente adquiridas pelos(as) docentes, os saberes cotidianos e a formação geral são relevantes para sua atuação na educação básica. Em se tratando da educação das pessoas com necessidades educacionais especiais deve-se ressaltar que a formação em serviços constitui-se num aspecto essencial aos professores que atuam com o diferente. Partindo dessa premissa, Silva e col. (2009) sugerem que "entendeu-se também que ter cursado uma disciplina que tratasse das questões referentes às necessidades educacionais especiais foi um diferencial na predominância destes saberes" (p.492).

Isso reforça a tese de que há uma veemente necessidade de se investir na formação docente, principalmente quando me refiro a educação dos estudantes com deficiências no ensino regular.

Em minhas reflexões, quando do meu ingresso em aulas de Educação Física, em especial no diálogo que tive com alguns docentes, confesso ter ficado perplexo, pois embora não haja nenhum impedimento legal no que se refere à participação dos(as) estudantes com deficiência visual, os(as) docentes não se propõem a preparar atividades físicas adaptadas que possibilitem a participação desses(as) nas atividades esportivas e de lazer.
Penso que, diante dessa análise, seja acerca da literatura especializada, seja ainda diante das observações em escolas, bem como no decorrer das entrevistas que fiz com seis estudantes deficientes visuais incluídos(as) no ensino regular fundamental e médio, falta aos docentes da Educação Física Escolar:

- Postura profissional no sentido de que esse componente curricular possa ser mais respeitado entre os segmentos da comunidade escolar;

- Diante de minhas percepções, ao longo desse estudo, penso ainda que a coordenação e direção da escola devam olhar para a Educação Física como um componente curricular relevante ao processo de Inclusão Escolar dos(as) estudantes matriculados(as) no ensino regular;

- Assim, nesta pesquisa, penso que na comunidade escolar o componente curricular de Educação Física é tão importante quanto os demais. Para tanto, deve se configurar como um processo relevante à inclusão de todos(as) na Educação Básica, independentemente se esses(as) tenham ou não alguma deficiência física, sensorial, motora ou múltipla.

Nesse estudo sou partidário de que 0 processo de Inclusão Escolar deve ocorrer em todo o sistema de ensino. Depende de todos(as) nós para que a Educação se torne verdadeiramente inclusiva, e, nesse sentido, libertadora, humana e humanizante. Nesse prisma, observa Freire (1992):

Inventamos a possibilidade de nos libertar na medida em que nos tornamos capazes de nos perceber como seres inconclusos, limitados, condicionados, históricos. [...] É preciso juntar a ela a luta política pela transformação da realidade (p.100)

Nas aulas de Educação Física, notei que a falta de formação dos(as) docentes no processo de inclusão de pessoas com deficiência visual pode levá-los(as) a extremos: de um lado colocálas em segundo plano, impedindo a participação efetiva na aula; de outro, rejeitar o trabalho com elas, estigmatizando-as. Neste sentido, González (2007) ressalta que:

As adaptações curriculares individualizadas devem reunir uma série de requisitos para poder atender adequadamente as necessidades educacionais especiais de cada aluno e evitar que ocorram situações de isolamento e marginalização como conseqüência de uma má aplicação do princípio de individualização (p. 31).

Destaco que a dificuldade da inclusão nas escolas não está apenas no(a) estudante deficiente visual, pois este(a) busca demonstrar suas capacidades e dar indicativos para melhoria do processo de Inclusão. Não é possível culpar 
os(as) estudantes pelo seu insucesso na escola; eles(as) são frutos de um sistema de ensino que ao longo de séculos foi excludente, seletista, conservador e marginalizador.

Percebi que a dificuldade da Inclusão pode estar, além das condições de trabalho docente (salas de aulas lotadas; recursos materiais limitados; baixo status profissional, valorização e remuneração), também na indisponibilidade de parte destes em aceitar mudanças, em respeitar o estranho, em compreender o diferente, o deficiente, inclusive quando estes(as) estão excluídos(as) das atividades físicas esportivas.

Explicitei ter identificado na pesquisa que nenhum dos(as) estudantes com deficiência visual entrevistados(as) e/ou observados(as) em campo quer estudar em salas especiais. Ao contrário, todos insistem em se manter no ensino regular.

Nas entrevistas os estudantes foram unânimes em afirmar que se sentem incluídos parcialmente no ensino regular, principalmente ao se referir às aulas de Educação Física Escolar. Assim, aprender a respeitar as individualidades, perceber que os(as) estudantes não são homogêneos e que aprendem de maneira diferenciada significa dizer que é possível aprender na e com a diversidade.

Neste sentido, considero que para avançar e consolidar a Inclusão é fundamental que as instâncias de poder, os sistemas de ensino, as escolas, os(as) docentes e a sociedade de modo geral mobilizem-se, sensibilizem-se, despojem-se dos preconceitos e estereótipos, assumindo a educação do deficiente e de todos(as) na pluralidade e na diversidade. Ou seja, parafraseando Mantoan (2003), virem a mesa, ou melhor, virem a cabeça.

Em síntese, assumo com Santos (1995) que todos e todas "queremos ser iguais quando as diferenças nos inferiorizam, porém queremos ser diferentes quando as igualdades nos descaracterizam".

\section{Referências}

BARROSO, J. Incluir sim, mas onde? Para uma reconceituação sóciocomunitária da escola pública. In: Rodrigues, D. (Org.). Inclusão e Educação: Doze olhares sobre a educação inclusiva. São Paulo: Summus Editorial, 2006.

BENITES, L. C.; SOUZA NETO, S.; HUNGER, D. O processo de constituição histórica das diretrizes curriculares na formação de professores de
Educação Física. Educação e Pesquisa, São Paulo, v. 34, n. 02, agosto de 2008 Disponível em: http://dx.doi.org/10.1590/S151797022008000200009. Acesso em 03 set. 2009.

BRASIL. Parecer CNE/CP 009/2001 de 8 de maio de 2001. Diretrizes Curriculares Nacionais para formação de professores de educação básica, em nível superior, curso de licenciatura, de graduação plena. Documento nํ. 476, pp. 01-70, 2001.

BOGDAN, R. C.; BIKLEN, S. K. Investigação qualitativa em educação. Porto: Porto Editora, 1994.

CARVALHO, R. E. Educação inclusiva: com os pingos nos "is". 4 ed. Porto Alegre: Ed. Mediação, 2006.

COSTA, V. B. A Prática Social da Convivência Escolar Entre Estudantes Deficientes Visuais e seus Docentes: o estreito caminho em direção à inclusão. 2009. Dissertação (Mestrado em Educação) - Universidade Federal de São Carlos, São Carlos, 2009.

FREIRE, P. Pedagogia do oprimido. 17. ed., Rio de Janeiro: Paz e Terra, 1987.

FREIRE, P. Pedagogia da esperança: um reencontro com a pedagogia do oprimido. Rio de Janeiro: Paz e Terra, 1992.

FURINI, A. B. Processo de inclusão: a criança com necessidade educativa especial e os envolvidos. 2006. Dissertação (Mestrado em Educação) - Pontifícia Universidade Católica do Rio Grande do Sul, Porto Alegre, 2006.

GONÇALVES JUNIOR, L. Lazer e novas relações de trabalho em tempos de globalização: a perspectiva dos líderes das centrais sindicais do Brasil e de Portugal. 2003. Tese (Pós-Doutorado em Ciências Sociais) - Instituto de Ciências Sociais, Universidade de Lisboa, Lisboa, 2003.

GONZALEZ, E. A Educação Especial: conceito e dados históricos. In: GONZALES, E. (Org.). Necessidades educacionais específicas. Porto Alegre: ARTMED, 2007.

HUSSERL, E. Ideas: general introduction to pure phenomenology. Londres: Collier Macmillan Publisheres, 1975.

\section{LARROSA BONDÍA, J. Notas Sobre a} Experiência e o Saber de Experiência. Tradução de João Wandreley Geraldi. Campinas: UNICAMP, 2002.

LOPES, A. W. A.; VALDÉS, M. T. M. Formação de Professores de Educação Física que atuam com Alunos com Necessidades Educacionais Especiais (Deficiência Auditiva): uma experiência no ensino fundamental da rede pública de Fortaleza. Revista Brasileira Educação Especial, Marília, v. 9, n. 2, p.195-210, 2003. 
MACHADO, O. V. M. Pesquisa Qualitativa: modalidade fenômeno situado. In: BICUDO, M. A. V.; ESPOSITO, V. H. C. (Org.). Pesquisa Qualitativa em Educação. São Paulo, Editora UNIMEP, 1994

MANTOAN, M. T. E. Inclusão escolar: o que é? Por quê? Como fazer? São Paulo: Moderna, 2003.

MARTINS, J.; BICUDO, M. A. V. A Pesquisa Qualitativa em Psicologia: fundamentos e recursos básicos. São Paulo: Educ/Moraes, 1989.

MARTINS, J. Um enfoque fenomenológico do currículo: educação como poíesis. São Paulo: Cortez, 1992.

NEGRINE, A. S. Instrumentos de coleta de informações na pesquisa qualitativa. In: MOLINA NETO, V.; TRIVIÑOS, A. N. S. (Org.). A pesquisa Qualitativa na Educação Física: alternativas metodológicas. $2^{a}$ ed. Porto Alegre: Editora da UFRGS/Sulina, 2004.

OLIVEIRA; M. W.; STOTZ, E. N. Perspectivas de diálogo no encontro entre organizações não governamentais e instituição acadêmica: o convívio metodológico. In: Anais da 27ª Reunião da ANPED "Sociedade, Democracia e Educação: qual Universidade?” Caxambu, 2004.

RODRIGUES, D. A Educação Física perante a Educação Inclusiva: reflexões conceptuais e metodológicas. Boletim da Sociedade Portuguesa de Educação Física, Lisboa, n. 2425, p. 73-81, 2003. Disponível em: http://www.spef.pt. Acesso em 10 nov. 2008.

SANTOS, M. P.; PAULINO, M. M. Inclusão em Educação: Uma visão geral. In: Santos, M. P dos.; Paulino, M. M. (orgs.). Inclusão em Educação: Culturas, Políticas e Práticas. 2 ed. São Paulo: Cortez, 2008.

SILVA, C. S., SOUZA NETO, S., DRIGO, A. J. Os professores de Educação Física Adaptada e os saberes docentes. Motriz, Rio Claro, v. 15 n.3 p.481-492, jul./set. 2009. Disponível em: http://www.periodicos.rc.biblioteca.unesp.br/index. php/motriz/article/view/2132/2398.

VITALINO, C. R. Análise da Necessidade de Preparação Pedagógica de Professores de Cursos de Licenciatura Para Inclusão de Alunos com Necessidades Educacionais Especiais.

Revista Brasileira de Educação Especial, v.13, n. 3, Marília, 2007.

Esse artigo foi apresentado em Sessão Temática no VI Congresso Internacional de Educação Física e Motricidade Humana e XII Simpósio Paulista de Educação Física, realizado pelo Departamento de Educação Física do IB/UNESP Rio Claro, SP de 30/4 a 03/5 de 2009.
Endereço:

Vanderlei Balbino da Costa

R. Dr. Eugênio de A. Egas, 330 Vila Brasília

São Carlos SP Brasil

13566-611

Telefone: (16) 9169.0307 / (16) 3415.179

e-mail: vanderleibalbino@gmail.com

Recebido em: 10 de fevereiro de 2009.

Aceito em: 03 de abril de 2009.

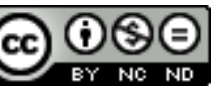

Motriz. Revista de Educação Física. UNESP, Rio Claro, SP, Brasil - elSSN: 1980-6574 - está licenciada sob Licenca Creative Commons 